\title{
Protein stability effects of a complete set of alanine substitutions in Arc repressor
}

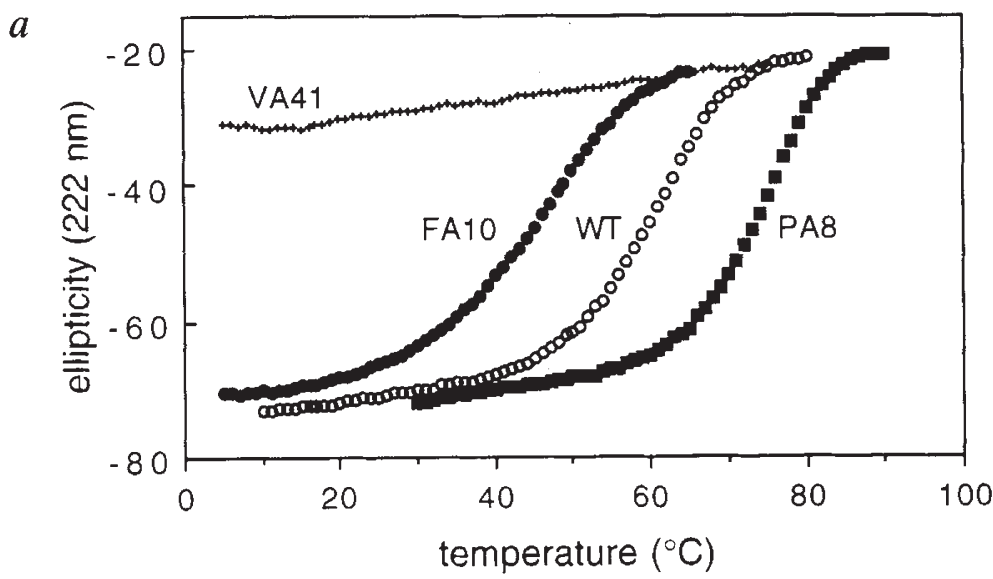

$b$

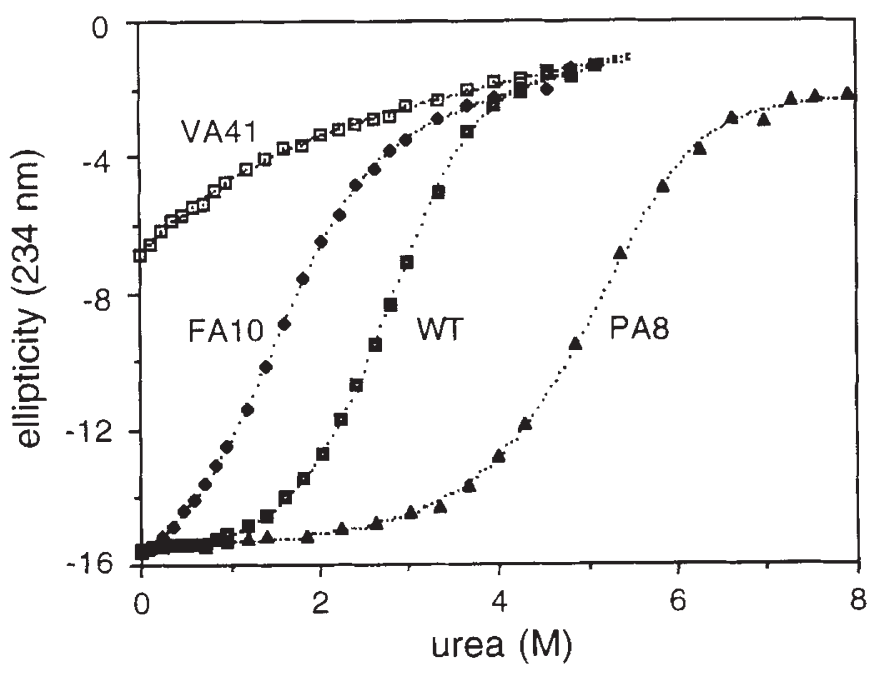

Marcos E. Milla, Bronwen M. Brown and Robert T. Sauer

Nature structural Biology 1, 518-523.

Figs $2 \& 3$ were printed incorrectly. The correct versions are printed below.
Fig. 2 Thermal denaturation $(a)$ and urea denaturation $(b)$ of the VA41-st11, FA10-st6, Arc-st 6 and PA8-st 6 proteins. The dotted lines in $b$ represent theoretical curves for a $\mathrm{N}_{2} \Leftrightarrow 2 \mathrm{U}$ unfolding reaction ${ }^{11}$.

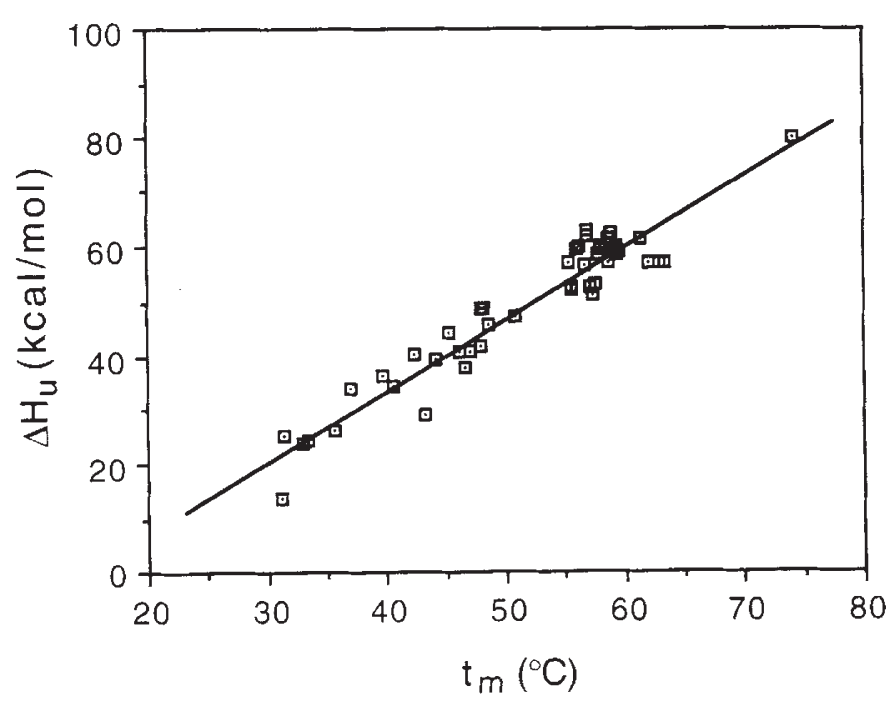

Fig. 3 Plot of $\Delta \mathrm{H}_{4}$ as a function of $t$ for the alanine mutants, Arc-st6, and Arc-st11. For a set of proteins having varying stabilities but having the same $\Delta C_{p}$ and the same enthalpy of unfolding at $0{ }^{\circ} \mathrm{C}\left(\Delta \mathrm{H}_{0}\right)$, the enthalpy of unfolding at the $t$ will be equal to $\Delta C{ }^{*} t_{m}+\Delta H_{0}$. The line is from a linear regression fit of the data with $\Delta \mathrm{C}=1.31( \pm 0.05) \mathrm{kcal} \mathrm{mol}^{-1} \mathrm{deg}^{-1}$ and $\Delta \mathrm{H}_{0}=-8.8( \pm 3.0) \mathrm{kcal} \mathrm{mol}^{-1} . \Delta \mathrm{C}_{\text {nd }}$ and $\Delta \mathrm{H}_{0}$ for unfolding of wild-type Arc have been estimated to be $1.6 \mathrm{kcal} \mathrm{mol}^{-1} \mathrm{deg}^{-1}$ (with a lower limit of $1.2 \mathrm{kcal} \mathrm{mol}^{-1} \mathrm{deg}^{-1}$ ) and $-15.4 \mathrm{kcal}$ $\mathrm{mol}^{-1}$, respectively, under slightly different conditions ${ }^{11}$.

structural biology volume 1 number 11 november 1994 